\title{
An Improved Current-Sensorless Method for Induction Motor Drives Applying Hysteresis Current Controller
}

\author{
Cuong Dinh Tran ${ }^{1 *}$, Pavel Brandstetter ${ }^{2}$, Minh Chau Huu Nguyen ${ }^{3}$, \\ Sang Dang Ho ${ }^{4}$, Phuong Nhat Pham ${ }^{5}$, Bach Hoang Dinh ${ }^{6}$ \\ ${ }^{1,6}$ Power System Optimization Research Group, Faculty of Electrical and Electronics Engineering, Ton Duc Thang \\ University, Ho Chi Minh City, Vietnam \\ ${ }^{4}$ Faculty of Electrical and Electronics Engineering, Ton Duc Thang University, Ho Chi Minh City, Vietnam \\ ${ }^{2,3,5}$ Faculty of Electrical Engineering and Computer Science, VSB-Technical University of Ostrava, Czech Republic \\ ${ }^{3}$ Faculty of Aeronautical electronics - Telecommunications engineering, Vietnam Aviation Academy, Vietnam
}

\begin{tabular}{l} 
Article Info \\
\hline Article history: \\
Received Sep 17, 2019 \\
Revised Jan 23, 2021 \\
Accepted Jan 27, 2021 \\
\hline
\end{tabular}

\section{Keywords:}

Current sensorless

Estimated currents

Hysteresis controller

Induction motor

Indirect field-oriented control.

\begin{abstract}
A novel strategy based on the feed-forward field-oriented control (FOC) method is proposed for the Hysteresis Current technique to control the induction motor (IM) drive without current sensors (CSs). A control scheme is proposed to estimate stator currents from reference rotor flux, rotor flux angle, and state variables as a replacement for the feedback-signal of CSs used in the hysteresis current controller (HCC). Here the rotor flux angle component is extracted from the feed-forward FOC loop. MATLAB/Simulink is applied to implement the simulations under many different operating conditions. The simulation results demonstrated the feasibility of the proposed method to obtain high performance in controlling the IM drives without the current sensors.
\end{abstract}

Copyright () 2021 Institute of Advanced Engineering and Science. All rights reserved.

\section{Corresponding Author:}

Cuong Dinh Tran,

Power System Optimization Research Group, Faculty of Electrical and Electronics Engineering,

Ton Duc Thang University, Ho Chi Minh City, Viet Nam.

Email: trandinhcuong@tdtu.edu.vn

\section{Nomenclature}

$\Psi_{S}^{S} \quad$ Stator flux vector in $[\alpha, \beta]$ coordinate system

$\Psi_{R}^{S} \quad$ Rotor flux vector in $[\alpha, \beta]$ coordinate system

$i_{S}^{S} \quad$ Stator current vector in $[\alpha, \beta]$ coordinate system

$i_{R}^{S} \quad$ Rotor current vector in $[\alpha, \beta]$ coordinate system

$\boldsymbol{u}_{S}^{S} \quad$ Stator voltage vector in $[\alpha, \beta]$ coordinate system

$u_{S \alpha}, u_{S \beta}$ Stator voltage component in $[\alpha, \beta]$ system

$u_{S x}, u_{S y}$ Stator voltage component in $[\mathrm{x}, \mathrm{y}]$ system

$u_{a}, u_{b}, u_{c}$ Stator voltage component in [a, b, c] system

$i_{S x} \quad$ Flux current component

$i_{S y} \quad$ Torque current component

$R_{S}, R_{R} \quad$ Stator and rotor resistance

$L_{S}, L_{R} \quad$ Stator and rotor inductance

$L_{m} \quad$ Magnetizing induction 


$\begin{array}{ll}T_{R} & \text { Rotor time constant } \\ \omega_{m} & \text { Mechanical angular speed } \\ p & \text { Pole pair number } \\ \psi_{R} & \text { Nominal rotor flux } \\ \gamma & \text { Rotor flux angle }\end{array}$

\section{INTRODUCTION}

In the past several decades, due to advantages about the size, low cost, and power control capability, the IM combined with modern control methods replaced DC motor in numerous industrial applications [1]. In modern control techniques, the scalar control and field-oriented control (FOC) are the two most popular groups for controlling the speed and the torque of IM drives.

Scalar control is appropriate for simple applications; however, the main disadvantage here is that it is only effective with a steady-state during the operation, and the torque of IM cannot be appropriately controlled in this method [2], [3]. The FOC strategy is applied in many complex industrial applications by its ruggedness and high reliability. This method's idea relies on the control of the stator current space vector by two independent perpendicular components, $\mathrm{i}_{\mathrm{Sx}}$, and $\mathrm{i}_{\mathrm{Sy}}$ like similar to separately excited DC motor. Here $\mathrm{i}_{\mathrm{Sx}}$ component will maintain the rotor flux at a specific reference value; on the other, the torque will be adjusted by isy component. The advantage of the FOC method is the capability to control exactly both the rotor speed and the torque at the same time. Moreover, the IM drive applied the FOC method also achieve high performance during transient conditions. However, the success of the FOC method depends completely on the accuracy of machine parameters in the various operation condition [2]-[8].

The function of the FOC algorithm is to receive the required information of the rotor speed and then provide the reference control signal, e.g., reference voltage, reference current, to the Pulse Width Modulation (PWM) inverter or hysteresis current (HC) controlled inverter. This process is called the FOC loop, which belongs to the closed-loop type. In this loop, the control process requires the feedbacks signal from sensors such as rotor speed, stator currents, and stator voltages. Certainly, the precision of feedback signals plays a key role in control algorithms. In this paper, the lack of feedback current signal due to the damaged sensor is concentrated. During the operation of the IM drive, if the current sensor is broken, that will lead the incorrect control for the whole drive system. Thus, to improve the high performance of the IM drive during the operation, it needs a solution against the failures of the current sensor. And the current sensorless is a backup solution to replace the faulty signal of CSs with a suitable estimated signal [9], [10].

In the paper [11], the IM drive based on the FOC technique uses an observer to estimate state variables without AC current sensors. The observer receives the feedback signals from DC-link voltage, DC link current, and speed sensor to implement the control method. The simulation results demonstrated the stable operation of the IM drive in the normal speed ranges, but the rotor speed fluctuates in the high-speed ranges. Another method only based on voltage scalar and measured rotor speed in the control speed of the IM drive without CSs is presented in the paper [12]. This method has a simpler structure and faster response than the FOC method. However, the effectiveness of speed control is worse than the FOC method; there is a disturbance of rotor speed when a change in load torque occurs. As a different approach, the paper [13] presents a direct predictive control scheme without CSs, here a double loop system is implemented, and the future stator currents are predicted by the voltage signal, rotor speed signal, and machine parameters. However, the slow response to reach reference speed is a disadvantage of this method. The paper [14] proposes a current sensorless technique for controlling IM drives. The estimated stator currents are calculated directly from the differential equations of stator and rotor current. The effectiveness of this method is demonstrated in various operating conditions; however, the characteristic of rotor speed is not stable under the pulse torque condition.

In this paper, an improved algorithm is proposed to calculate the stator currents from the voltage signal, rotor speed, and rotor flux in the FOC control loop. Here, the feed-forward FOC is applied in the control loop, and real current signals will be replaced by stator currents of the estimator in the comparison algorithm of the HCC. The feasibility of the proposed method will be demonstrated by simulation results in MATLAB/Simulink software.

\section{THE CURRENT SENSORLESS (CSL) ALGORITHM}

In this section, the feed-forward FOC technique and current sensorless method will be described.

\subsection{The Feed-forward FOC technique based on hysteresis current controller.}

Generally, The FOC is a method based on the DC motor idea that means the rotor flux and the torque is controlled separately by two elements $i_{S x}$, and $i_{S y}$. Here $x$-axis of the rotating $[x, y]$ coordinate system is the same axis with the rotor flux. 
The most important step of the FOC technique is determining the rotor flux space vector: the modulus and angle $\gamma$. Based on ways to determine the rotor flux angle, FOC techniques are classified into direct fieldoriented control (DFOC) and Indirect field-oriented control (IFOC). With DFOC methods, the rotor flux angle can be measured directly from Hall sensors or calculated directly from voltage and current signals in the voltage model of the IM. In IFOC methods, the angle $\gamma$ is estimated from measured signals of current sensors and a speed sensor in the current model of the IM, or only measured speed signal.

In this paper, due to the stator current signals from sensors will be not used for the control of the IM drive, so the IFOC technique receiving an only feedback signal from speed sensor called Feed-Forward FOC method will be applied to calculate and provide the reference currents to the current controller [6]. Here, the typical current controller uses the hysteresis modulation based on the comparison between reference stator currents and measured currents from sensors to generate the control pulse signals to the inverter's six switches [15].

The IM can be controlled by the Feed-Forward FOC technique shown in Figure 1. The reference element $i_{S x}^{*}$ can be estimated from the nominal rotor flux constant as Eq. (1).

$$
i_{S x}^{*}=\frac{1}{L_{m}}\left(\psi_{R}^{*}+T_{R} \frac{d \psi_{R}^{*}}{d t}\right)=\frac{\psi_{R}^{*}}{L_{m}}
$$

The PI controller is used to estimate the reference electrical torque $T_{e}^{*}$ from the difference between reference speed and feedback speed signal. The reference component can then be obtained from the relationship of the reference torque and rotor flux as Eq. (2).

$$
i_{S y}^{*}=\frac{2}{3 p} \frac{L_{R}}{L_{m}} \frac{T_{e}^{*}}{\psi_{R}^{*}}
$$
below Eq:

The element rotor flux angle $\gamma$ can be determined from the measured rotor speed and the rotor slip as

$$
\begin{aligned}
& \gamma=\int\left(p \cdot \omega_{m}+\omega_{s l}\right) d t \\
& \text { where }: \omega_{s l}=\frac{L_{m} i_{S y}^{*}}{T_{R} \psi_{R}^{*}}
\end{aligned}
$$

The reference stator current signals in the three-phase [a, b, c] system will be transformed from the rotating coordinate $[\mathrm{x}, \mathrm{y}]$ system by reverse Clarke-Park's transformation as Eq. (4).

$$
\begin{aligned}
& i_{a}^{*}=i_{S x}^{*} \cos (\gamma)-i_{S y}^{*} \sin (\gamma) \\
& i_{b}^{*}=i_{S x}^{*} \cos \left(\gamma-120^{\circ}\right)-i_{S y}^{*} \sin \left(\gamma-120^{\circ}\right) \\
& i_{c}^{*}=i_{S x}^{*} \cos \left(\gamma+120^{\circ}\right)-i_{S y}^{*} \sin \left(\gamma+120^{\circ}\right)
\end{aligned}
$$

In the current controller, real values of stator currents from sensors will be compared to the reference stator currents, and their errors are applied to generate switching commands for the inverter to implement the speed control in the IM drive system.

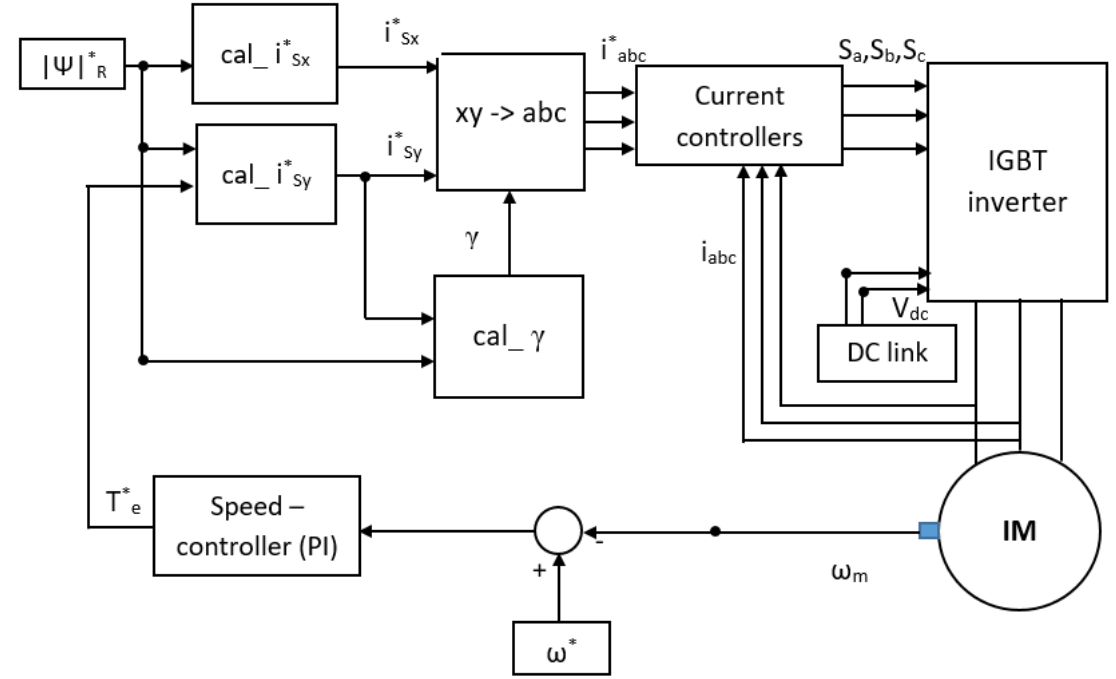


Figure 1. Block diagram of the Feed-forward FOC technique with current sensors.

\subsection{The Feed-forward FOC technique based on hysteresis current controller without current sensors.}

Figure 2 presents a sensorless control scheme where the estimated current signals will replace the measured stator current signals.

The stator current estimator's inputs comprise the rotor speed $\omega_{\mathrm{m}}$ signal, the amplitude of rotor flux, the rotor flux angle, and the stator voltages where these three-phase voltages $\left[u_{a}, u_{b}, u_{c}\right]$ will be determined from the DC-link voltage and switching-pulse signals of the current controller.

We can obtain the rotor flux in stationary $[\alpha, \beta]$ coordinate system in two ways: using the current model as in (5), or applying the voltage model as in (6), [16].

$$
\begin{gathered}
\boldsymbol{\psi}_{R}^{S}=\int\left[\left(j \omega_{R}-\frac{1}{T_{R}}\right) \boldsymbol{\psi}_{R}^{S}+\frac{L_{m}}{T_{R}} \boldsymbol{i}_{S}^{S}\right] \\
\boldsymbol{\psi}_{R}^{S}=\frac{L_{R}}{L_{m}}\left[\int\left(\boldsymbol{u}_{S}^{S}-R_{S} \boldsymbol{i}_{S}^{S}\right) d t-\frac{L_{S} L_{R}-L_{m}^{2}}{L_{R}} \boldsymbol{i}_{S}^{S}\right]
\end{gathered}
$$

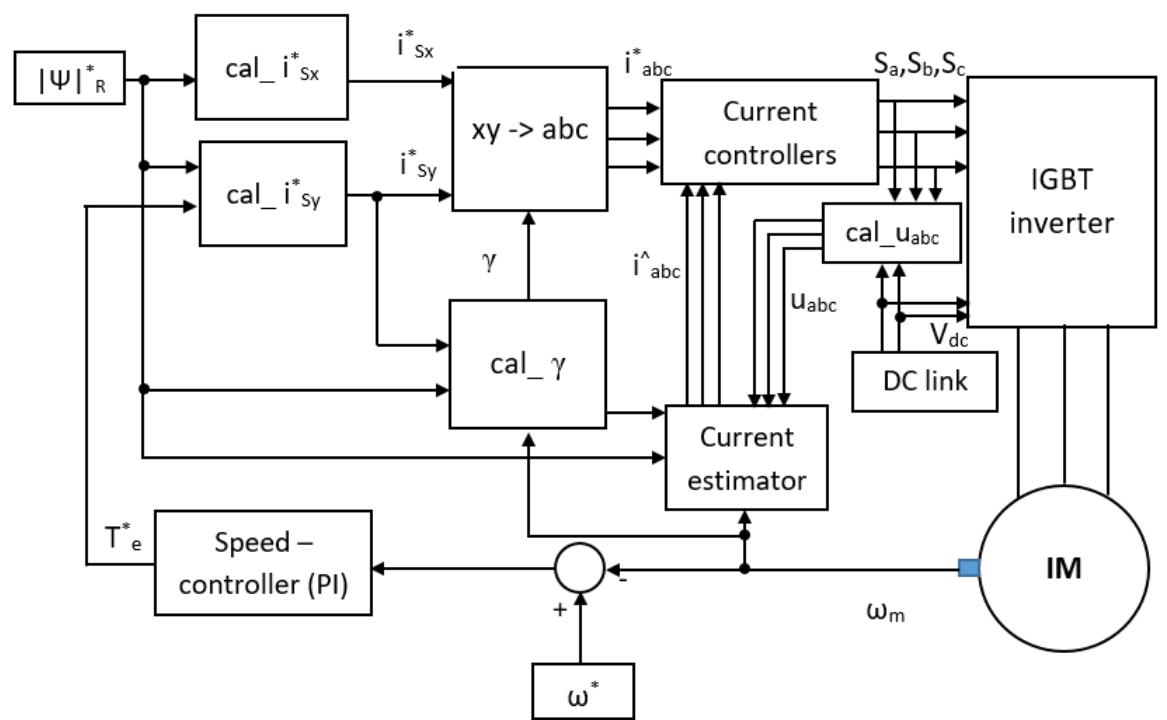

Figure 2. Block diagram of the Feed-forward FOC without current sensors.

By substitution of (5) into (6), we can derive the stator current estimation equation as below:

$$
\begin{aligned}
& \frac{d \boldsymbol{i}_{S}^{S}}{d t}=A_{1} \boldsymbol{u}_{S}^{S}-A_{2} \boldsymbol{i}_{S}^{S}+A_{3} \boldsymbol{\psi}_{R}^{S}-j A_{4} \omega_{R} \boldsymbol{\psi}_{R}^{S} \\
& A_{1}=\frac{L_{m}}{L_{S} L_{R}-L_{m}^{2}} ; \mathrm{A}_{3}=\frac{L_{m}^{2}}{T_{R} L_{R}\left(L_{S} L_{R}-L_{m}^{2}\right)} ; \\
& A_{2}=\left[\frac{\left(\frac{L_{R} R_{S}}{L_{m}}+\frac{L_{m}}{T_{R}}\right)}{\frac{L_{R}\left(L_{S} L_{R}-L_{m}^{2}\right)}{L_{m}^{2}}}\right] ; \mathrm{A}_{4}=\frac{L_{m}^{2}}{L_{R}\left(L_{S} L_{R}-L_{m}^{2}\right)}
\end{aligned}
$$

Normally, the rotor flux will be calculated from the current model (6) and transfer into the stator current estimation equation (7), [17]-[20]. However, because IMD in the sensorless mode does not receive the feedback current signals from the current sensor, therefore this way is impossible. Thus, the rotor flux of the current model will be replaced by the rotor flux space vector from the feed-forward FOC loop. The result as the estimated stator current can be calculated as (8).

$$
\frac{d \boldsymbol{i}_{S}^{S}}{d t}=A_{1} \boldsymbol{u}_{S}^{S}-A_{2} i_{S}^{S}+A_{3} \boldsymbol{\psi}_{R}^{* S}-j A_{4} \omega_{R} \boldsymbol{\psi}_{R}^{* S}
$$

By using Eq.(8), the IM drive system can be controlled to adapt to the speed and torque changes by the HCC without CSs. The number of differential equations required for this method is two; it is less than the 
four differential equations of the current estimation method, which is presented in [14]. Thus, it is possible to reduce the complexity of the current estimation algorithm to facilitate the control aspect of the IMD.

\section{RESULTS AND ANALYSIS}

To demonstrate the feasibility of the proposed method, simulations in Matlab/Simulink will be implemented. Here, the model of IM from the software library will be applied with machine parameters listed as follows:

$\mathrm{P}_{\mathrm{n}}=4.0 \mathrm{~kW}, \omega_{\mathrm{n}}=1430 \mathrm{rpm}, \mathrm{p}=2$.

$\mathrm{I}_{\mathrm{Sn}}=8.4 \mathrm{~A}, \mathrm{U}_{\mathrm{Sn}}=400 \mathrm{~V}, \Psi_{\mathrm{Sn}}=1.23 \mathrm{~Wb}$.

$\mathrm{R}_{\mathrm{S}}=1.405 \Omega, \mathrm{R}_{\mathrm{R}}=1.395 \Omega$,

$\mathrm{L}_{\mathrm{S}}=0.178 \mathrm{H}, \mathrm{L}_{\mathrm{R}}=0.178 \mathrm{H}$,

$\mathrm{L}_{\mathrm{m}}=0.172 \mathrm{H}, \mathrm{T}_{\mathrm{R}}=0.1276 \mathrm{~s}$.

Model simulation of the IM drive system is described in Figure 3. Here, the switching inverter is controlled by the HC method. The current estimation unit in Figure 4. receives input signal: the voltages, the measured rotor speed, the reference rotor flux, and rotor flux angle to calculate the stator currents. The estimated stator current will be sent back to the FOC loop to implement the inverter control demand corresponding to the hysteresis-current control method.

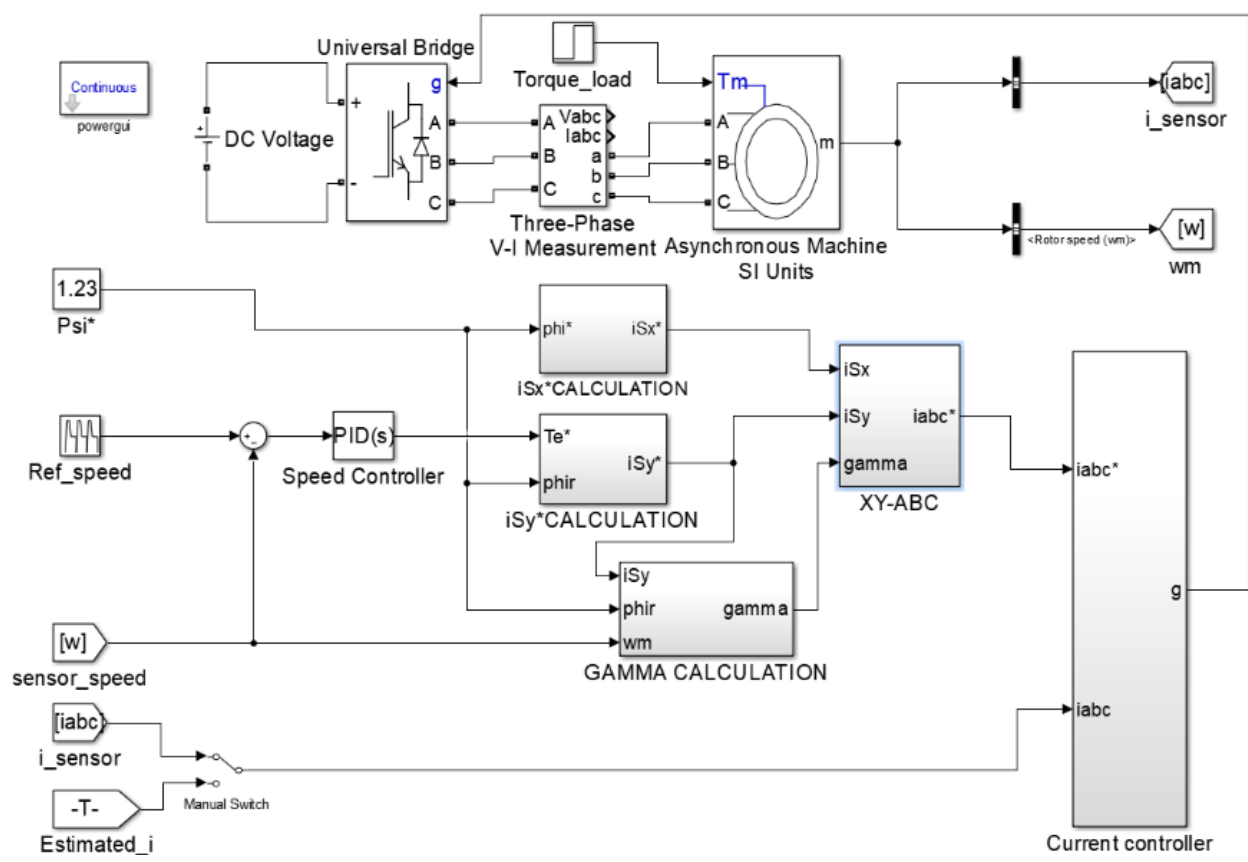

Figure 3. Model simulation of IM drive system applied HC method.

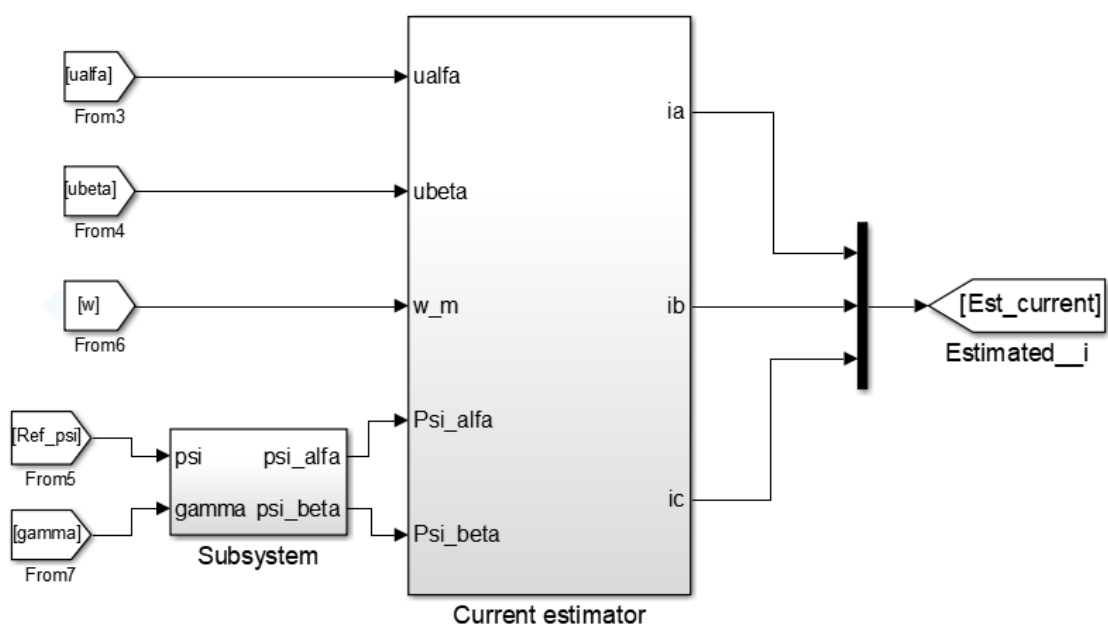


Figure 4. Block diagram of current estimation

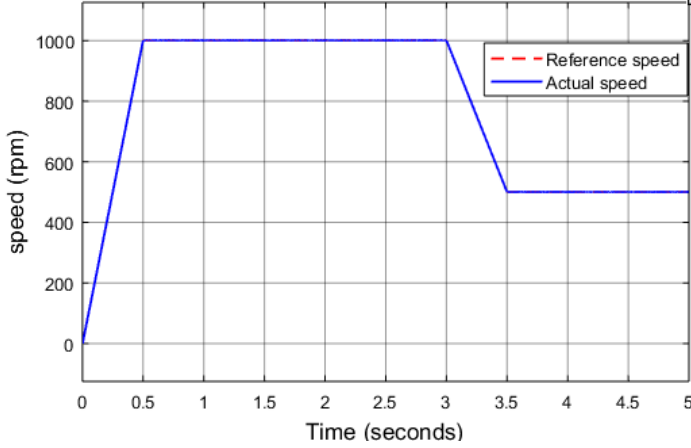

(a)

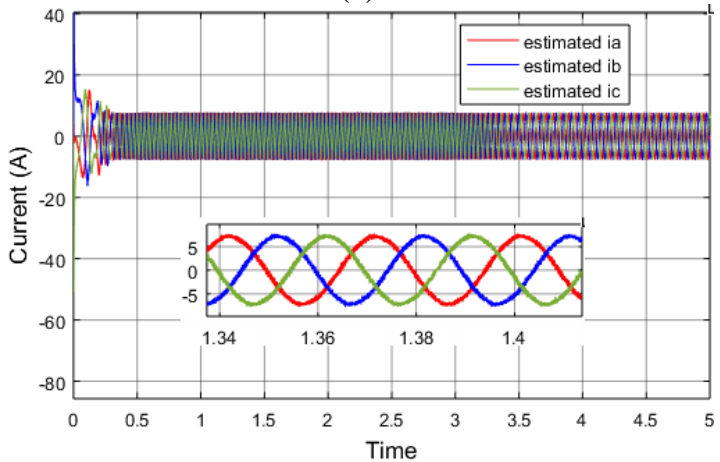

(b)

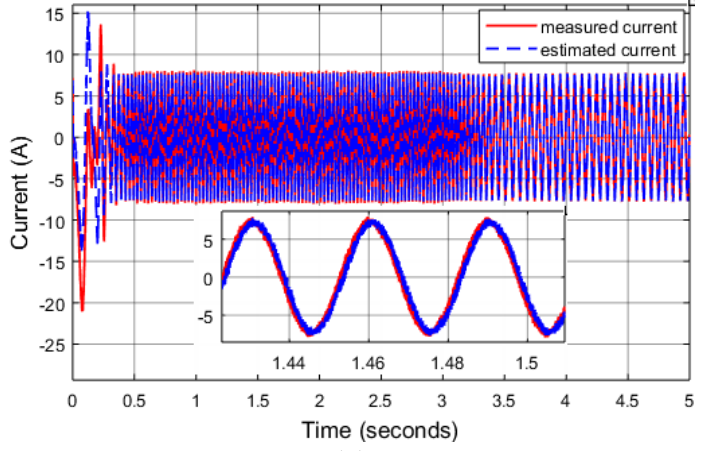

(c)

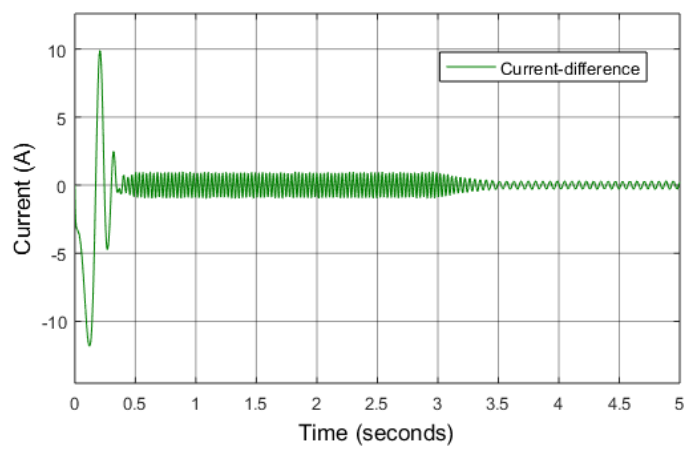

(d)

Figure 5. The operation of IM applying the CSL technique in no-load condition:

(a) Rotor speed at 70\% - 35\% rating speed, (b) Three-phase current of estimation, (c) Comparison between A-phase measured and estimated current, (d) Difference between A-phase measured and estimated current.

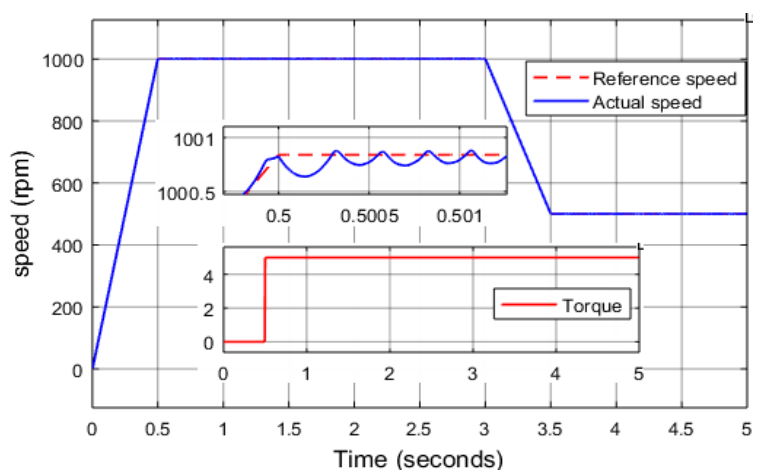

(a)

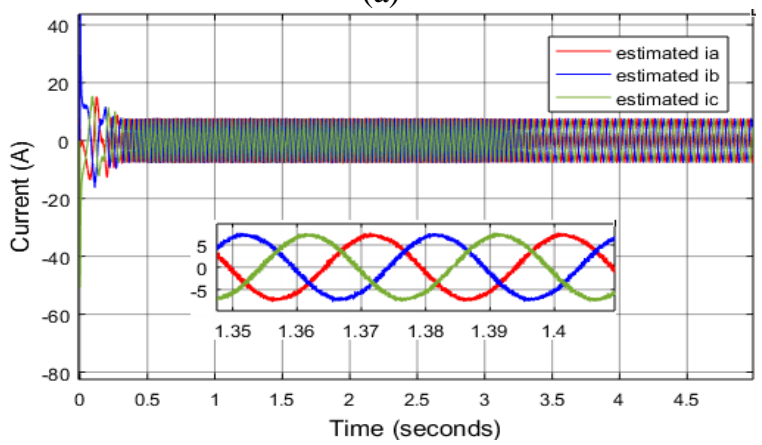

(b)

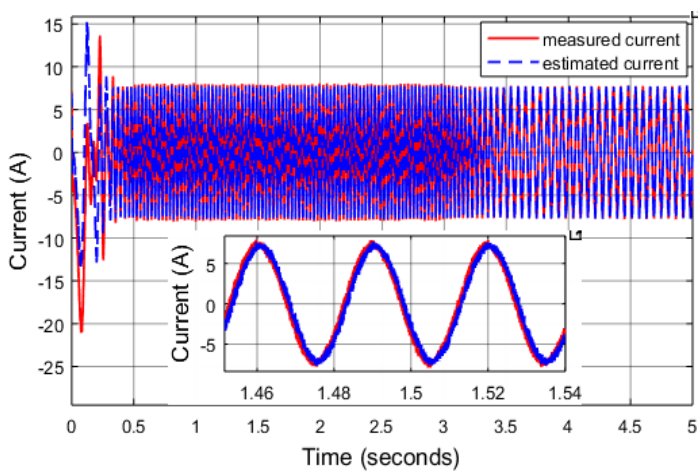

(c)

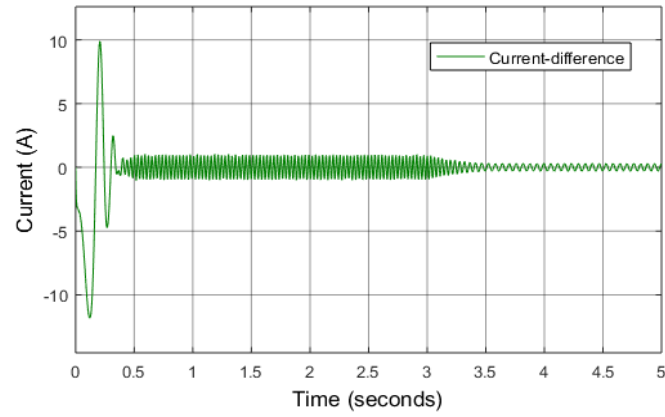

(d)

Figure 6. The operation of IM applying the CSL technique in torque load of 5 N.m condition: (a) Rotor speed at 70\% - 35\% rating speed, (b) Three-phase current of estimation, (c) Comparison between A-phase measured and estimated current, (d) Difference between A-phase measured and estimated current. 


\section{Case study 1:}

The operations of the IM drive will be simulated at the normal speed under many different load conditions. The rotor speed set in two reference speeds is $70 \%$ and $35 \%$ of the rating value, as in Figure 5 . Beginning with a no-load condition, the current controller compares the estimated stator current and reference stator current to generate the control signals to the switching inverter. Figure 5 shows the rotor speed responses of IM drive applying the current sensorless method. The actual rotor speed precisely follows the reference speed, and the estimated stator current is similar to the measured signal, from starting point time to 0.5 sec. The rotor speed increases from zero value to reference value; besides, the estimated stator current is calculated from the rotor speed. As a result, the transience of the estimated current occurred in a short time at the starting period, then the estimated current quickly returns stably state similar to the measured signal of sensors.

Next simulation, a torque load of 5 N.m is applied to the drive system at the time of $0.5 \mathrm{sec}$. The rotor speed, estimated stator current, and comparison result between measured and estimated current signals in the specific phase current were presented as in Figure 6. Similar to the previous case, the simulation results proved the stable and accurate operation of IM drive applying the current sensorless technique.

To prove the robustness of the proposed current sensorless method, a pulse torque of 5 N.m is applied to the simulation model. The simulation results in Figure 7 demonstrated that the IM drive system applying the current sensorless strategy still ensures the good capability to control the speed and torque, similar to cases using the CSs.

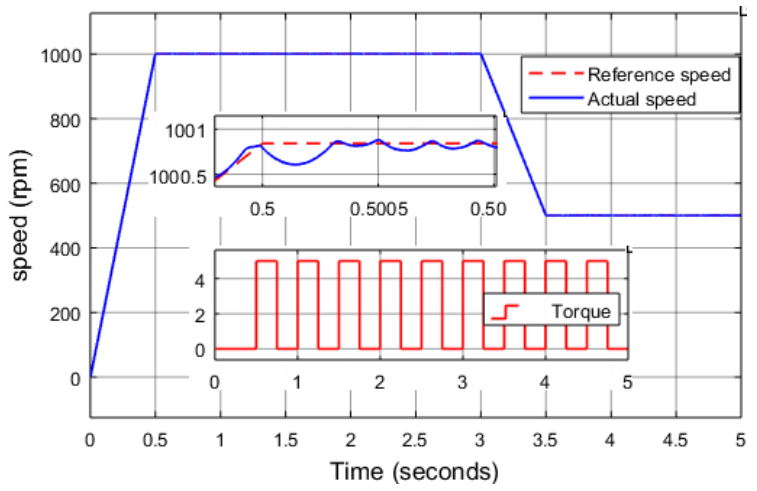

(a)

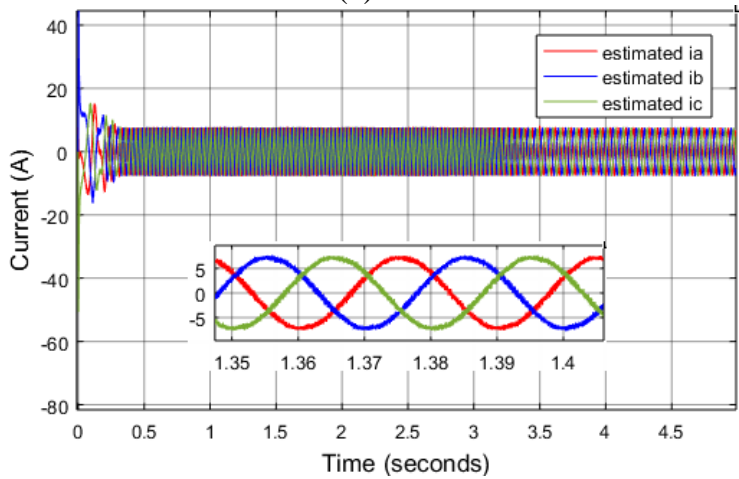

(b)

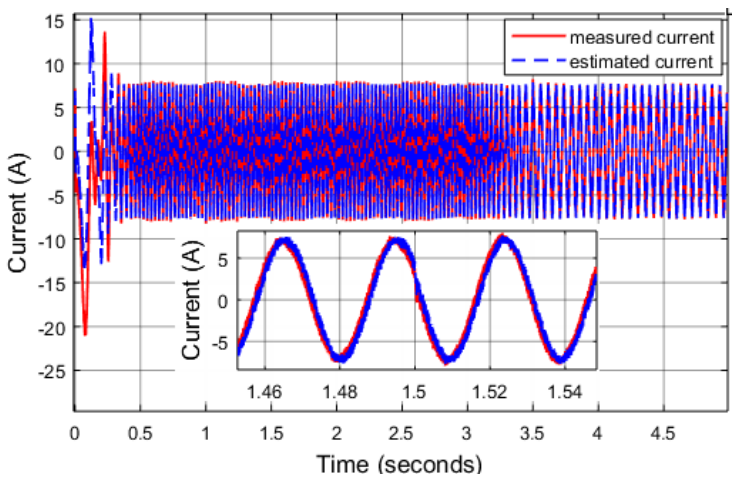

(c)

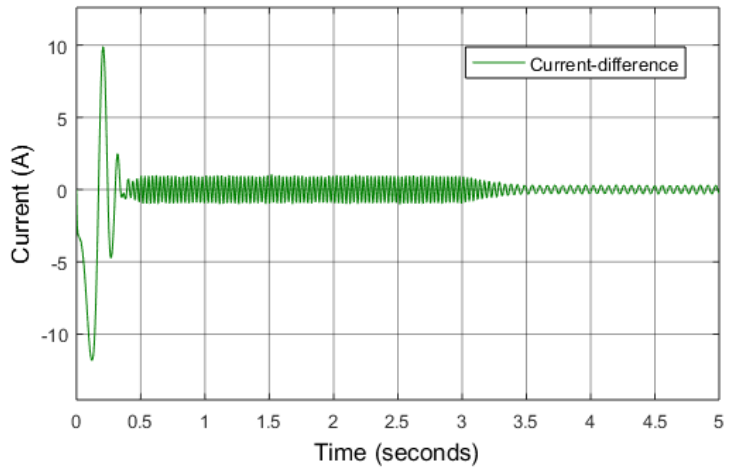

(d)

Figure 7. The operation of IM applying the CSL technique in pulse torque load of 5 N.m condition:

(a) Rotor speed at 70\% - 35\% rating speed, (b) Three-phase current of estimation, (c) Comparison between A-phase measured and estimated current, (d) Difference between A-phase measured and estimated current.

\subsection{Case study 2:}

The operations of the IM drive will be simulated at the low-speed zone under conditions as the same as the previous cases. The rotor speed set in two reference speeds is $20 \%$ and $10 \%$ of the rating value in these simulations. In sequence, the simulations are executed with no load condition, a load of 5 N.m condition, and a pulse load of 5 N.m condition. The simulation results are shown in Figure 8, Figure 9, Figure 10; due to the lower reference speed signal, therefore the overshoot of the estimated current in the transient state is smaller than in the previous case. Corresponding to the simulation results obtained, the effectiveness of the proposed is verified to replace the methods using CSs. 


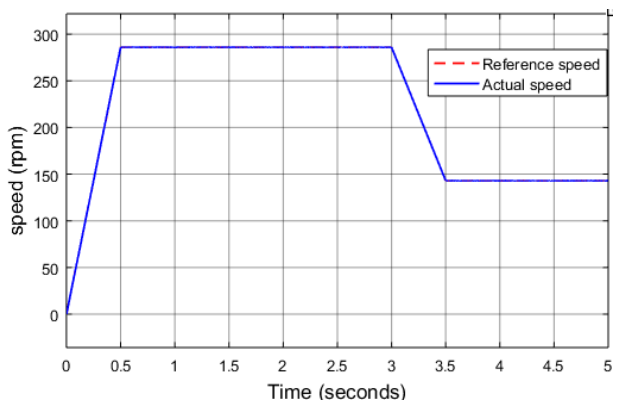

(a)

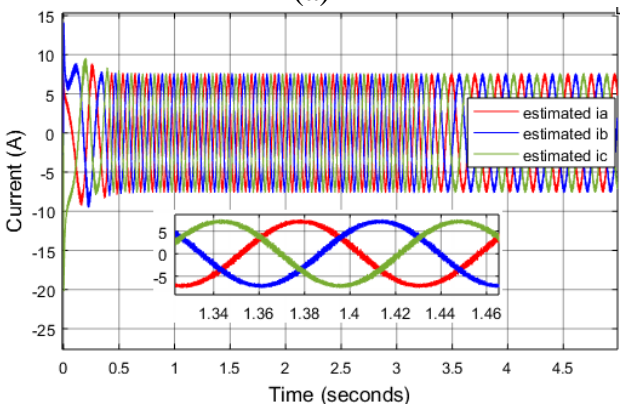

(b)

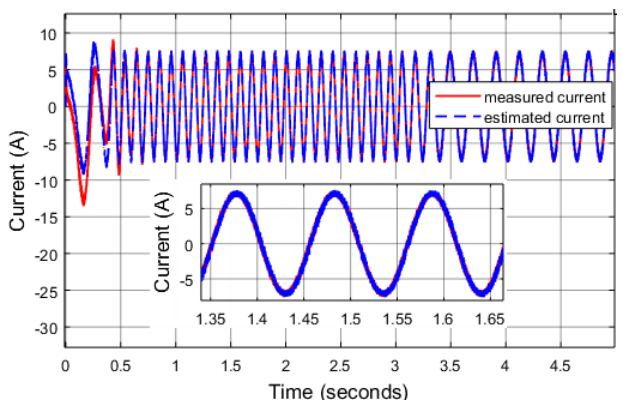

(c)

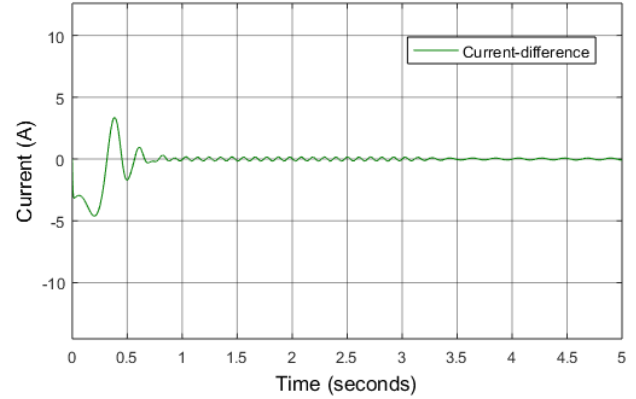

(d)

Figure 8. The operation of IM applying the CSL technique in no-load condition:

(a) Rotor speed at 20\% - 10\% rating speed, (b) Three-phase current of estimation, (c) Comparison between A-phase measured and estimated current, (d) Difference between A-phase measured and estimated current.

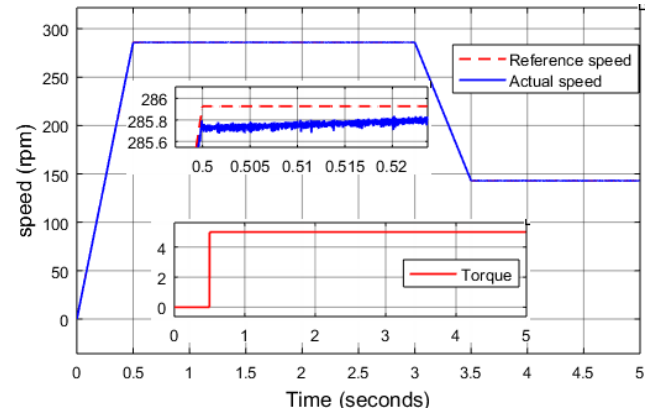

(a)

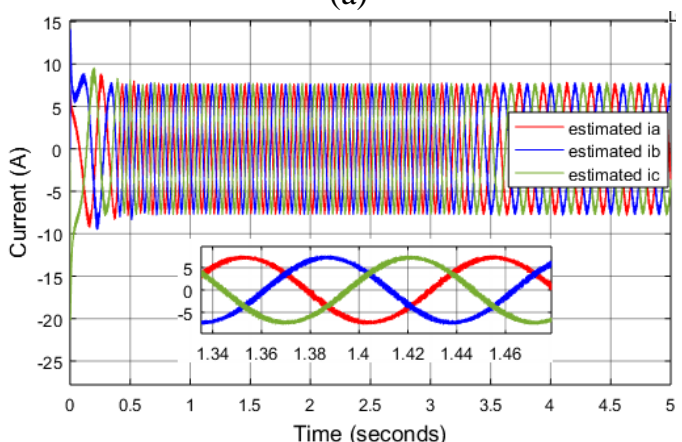

(b)

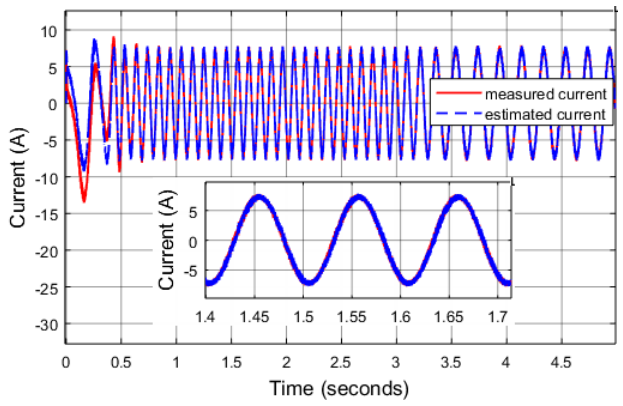

(c)

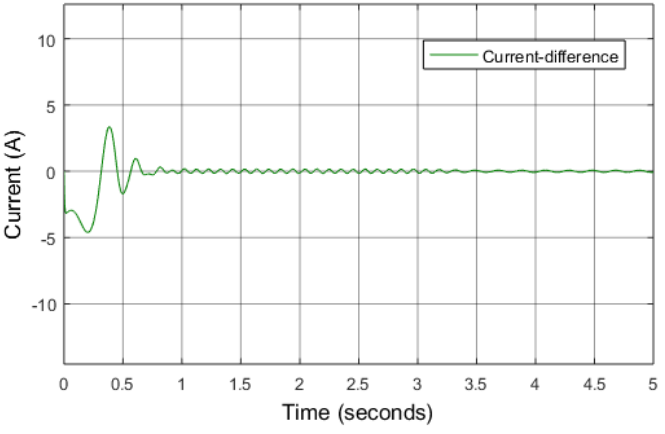

(d)

Figure 9. The operation of IM applying the CSL technique in torque load of 5 N.m condition:

(a) Rotor speed at 20\% - 10\% rating speed, (b) Three-phase current of estimation, (c) Comparison between A-phase measured and estimated current, (d) Difference between A-phase measured and estimated current. 


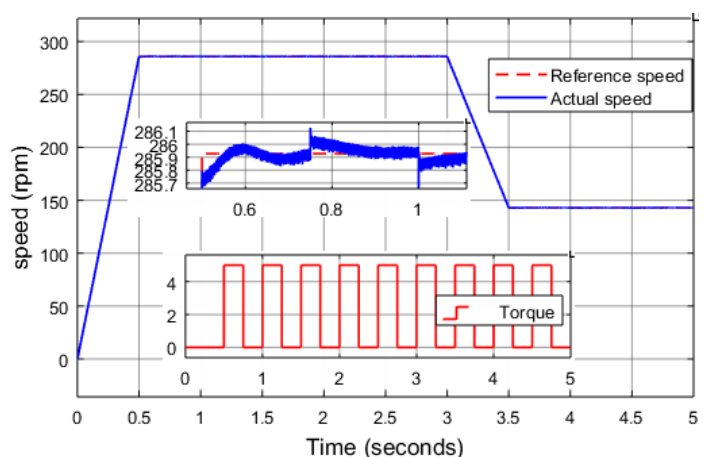

(a)

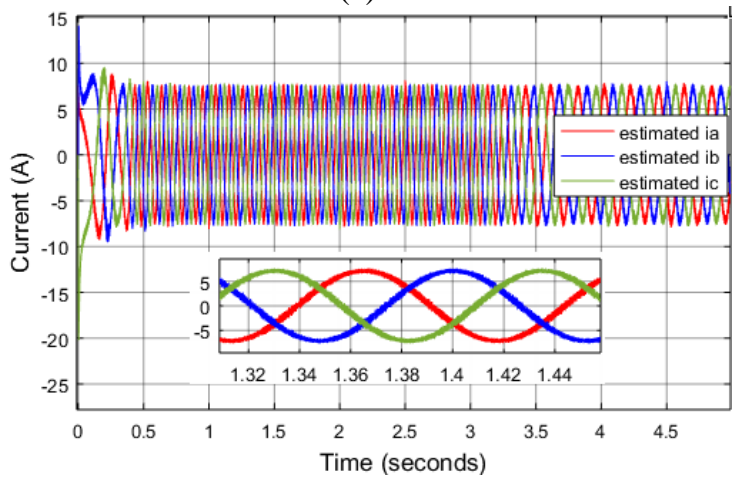

(b)

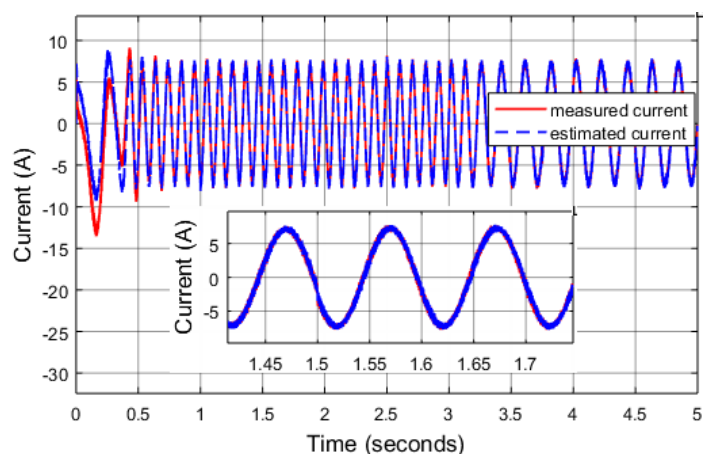

(c)

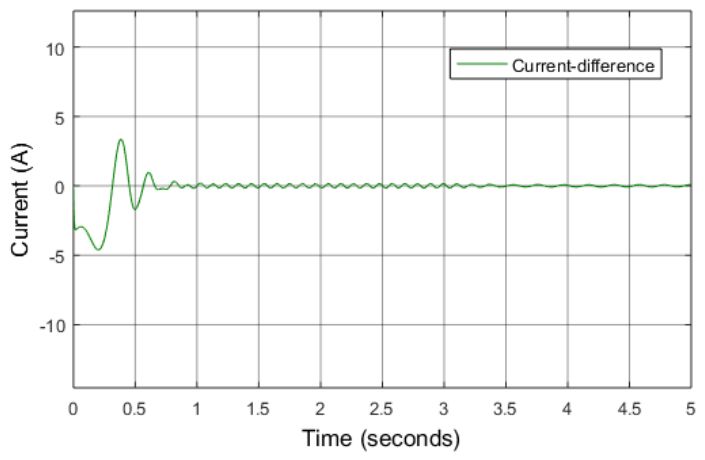

(d)

Figure 10. The operation of IM applying the CSL technique in pulse torque load of 5 N.m condition: (a) Rotor speed at 20\% - 10\% rating speed, (b) Three-phase current of estimation, (c) Comparison between A-phase measured and estimated current, (d) Difference between A-phase measured and estimated current.

\section{CONCLUSION}

An improvement of the current sensorless applying the IM drive based on the HC control technique is presented as the main content of this paper. The stator current used to replace the measured current is estimated from the voltage signal, measured rotor speed, reference rotor flux space vector, and machine parameters by the differential equation. Reference flux is applied in differential equations to reduce the complexity of the current estimation algorithm. The simulation results in MATLAB/Simulink environment verified the reliability and stability of the proposed strategy in controlling the speed and the torque of the IM drive. The proposed method's success depends on the accuracy of the rotor time constant $T_{R}$, which is affected by the motor's operating temperature; therefore, the estimated rotor time constant should be researched to improve the accuracy of the current sensorless method in the next researches.

\section{ACKNOWLEDGMENTS}

This work was supported by SP2021/70 - Research of modern control methods of AC drives, VSBTechnical University of Ostrava, 2021.

\section{REFERENCES}

[1] P. Vas, Sensorless vector and direct torque control. Oxford Univ, Oxford: Press, 1998.

[2] S. Melentjev, A. Belahcen, A. Kallaste, and T. Vaimann, "Overview of control methods of reluctance machines with sensors and sensorless," In 2014 55th International Scientific Conference on Power and Electrical Engineering of Riga Technical University (RTUCON), pp. 26-29, 2014.

[3] G. Kohlrusz and D. Fodor, "Comparison of scalar and vector control strategies of induction motors," Hungarian Journal of Industry and Chemistry, vol. 39, no. 2, pp. 265-270, 2011.

[4] K. Wang, Q. Ge, Y. Li, and L. Shi, "An improved current regulation scheme used in indirect rotor field oriented control for AC traction applications," In 2013 15th European Conference on Power Electronics and Applications (EPE), pp. 1-10, 2013.

[5] A. Kumar and T. Ramesh, "Direct field oriented control of induction motor drive," In 2015 Second International Conference on Advances in Computing and Communication Engineering, pp. 219-223, 2015.

[6] E. Levi, "High performance drives," LJMU - School of engineering, 2001/2002. 
[7] P. Shrawane, "Indirect field-oriented control of induction motor," In 12th IEEE International Power Electronics Congress, pp. 102-105, 2010.

[8] B. K. Nishad and R. Sharma, "Induction Motor Control using Modified Indirect Field Oriented Control," In 2018 8th IEEE India International Conference on Power Electronics (IICPE), pp. 1-5, 2018.

[9] C. D. Tran et al., "A Novel Speed and Current Sensor Fault-Tolerant Control Based on Estimated Stator Currents in Induction Motor Drives," International Review of Electrical Engineering (IREE), vol. 15, no. 5, pp. 344-351, 2020.

[10] Y. Yu, Y. Zhao, B. Wang, X. Huang, and D. Xu, "Current sensor fault diagnosis and tol-erant control for VSI-based induction motor drives," IEEE Transactions on Power Elec-tronics, vol. 33, no. 5, pp. 4238-4248, 2018.

[11] G. Barba, L. Glielmo, V. Perna, and F. Vasca, "Current sensorless induction motor observer and control for hybrid electric vehicles,” In Power Electronics Specialists Conference (PESC), IEEE 32nd Annual, vol. 2, pp. 1224-1229, 2001.

[12] M. Bierhoff and M. Göllner, "A current sensor less speed control algorithm for induction motors," In Industrial Electronics Society, IECON 2016-42nd Annual Conference of the IEEE, pp. 2606-2611, 2016.

[13] Y. Yu, X. Chen, and Z. Dong, "Current sensorless direct predictive control for induction motor drives," In 2017 IEEE Transportation Electrification Conference and Expo, Asia-Pacific (ITEC Asia-Pacific), pp. 1-6, 2017.

[14] C. D. Tran, P. Brandstetter, B. H. Dinh, S. D. Ho, and M. C. H. Nguyen, "Current-Sensorless Method for Speed Control of Induction Motor Based on Hysteresis Pulse Width Modulation Technique," Journal of Advanced Engineering and Computation 2, no. 4, pp. 271-280, 2018.

[15] N. Farah, M. H. N. Talib, Z. Ibrahim, S. M. Isa, and J. M. Lazi, "Variable hysteresis current controller with fuzzy logic controller based induction motor drives," In 2017 7th IEEE International Conference on System Engineering and Technology (ICSET), pp. 122-127, 2017.

[16] P. Brandstetter and M. Kuchar, "Rotor flux estimation using voltage model of induction motor," In 2015 16th International Scientific Conference on Electric Power Engineering (EPE), pp. 246-250, 2015.

[17] P. Brandstetter, "Sensorless control of induction motor using modified MRAS," International Review of Electrical Engineering (IREE), vol. 7, no. 3, 2012.

[18] T. Orlowska-Kowalska and M. Dybkowski, "Stator-current-based MRAS estimator for a wide range speed-sensorless induction-motor drive," IEEE Transactions on industrial electronics, vol. 57, no. 4, pp. 1296-1308, 2009.

[19] M. S. Zaky, M. Khater, H. Yasin, and S. S. Shokralla, "Review of different speed estimation schemes for sensorless induction motor drives," Journal of Electrical Engineering, vol. 8, no. 2, pp.102-40, 2008.

[20] C. W. Park and W. H. Kwon, "Simple and robust speed sensorless vector control of induction motor using stator current based MRAC," Electric Power Systems Research, vol. 71, no. 3, pp. 257-266 , 2004.

\section{BIOGRAPHY OF AUTHORS}

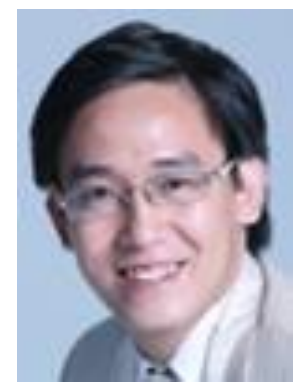

Cuong Dinh Tran was born in Ho Chi Minh City, Vietnam. He received an ME degree from Ho Chi Minh City University Of Technology, Vietnam, in 2008 and a Ph.D. degree in Electrical Engineering from VSB-Technical University of Ostrava, Czech Republic, in 2020. Now, he is a lecturer of the department of electrical and electronics engineering, Ton Duc Thang University, Ho Chi Minh City, Vietnam. His research interests are the application of modern control methods and intelligent algorithms in induction motor drives.

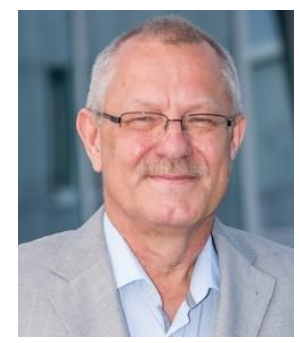

Pavel Brandstetter was born in Ostrava, Czech Republic, 1955, 1 June. He received the M.Sc. and Ph.D. degrees in Electrical Engineering from Brno University of Technology, Czech Republic, in 1979 and 1987, respectively. He is currently full professor in Electrical Machines, Apparatus and Drives and dean of Faculty of Electrical Engineering and Computer Science at VSB-Technical University of Ostrava. Research activities include modern control methods of AC drives, for example, sensorless control of the IM and PMSM drives using different types of the observers.

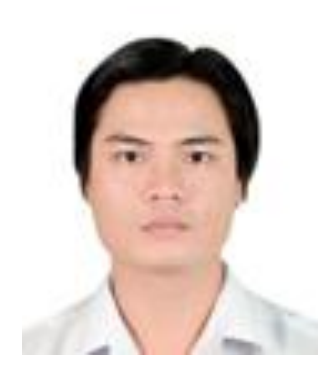

Minh Chau Huu Nguyen was born in Binh Duong, Vietnam. He graduated from the Military Technical Academy, Vietnam. He received his ME degrees in Automation engineering in 2012. Now, he is researching at the Faculty of Electrical Engineering \& Computer Science, VSB Technical University of Ostrava, Czech Republic. His research interests include an automatic control system, intelligent control system and electrical machine, apparatus and drives. 


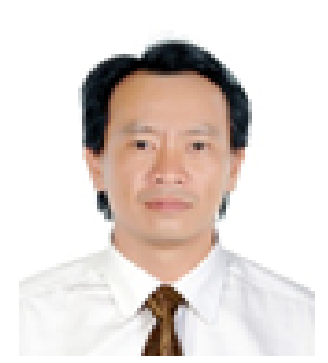

Sang Dang HO received ME degrees in Electrical Engineering from Vietnam National University - Ho Chi Minh City - University of Technology, in 2008. Now, he is a lecturer of the department of electrical and electronics engineering, Ton Duc Thang University, Ho Chi Minh City, Vietnam. His research interests are about optimization of the power system and electric machines control fields.

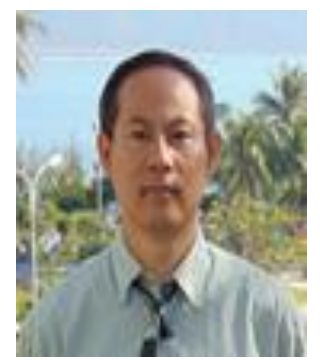

Bach Hoang Dinh received the Ph.D degree in Electrical Engineering from Heriot-Watt University, Edinburgh, United Kingdom in 2009. He received the BE and the ME degrees in Electrical Engineering from Vietnam National University - Hochiminh City in 1995 and 1998, respectively. Bach Dinh is currently the head of Electrical Engineering Department, Faculty of Electrical-Electronic Engineering at Ton Duc Thang University. His research interests are intelligent and optimal control, computer vision, robotics, power electronics, SCADA and industrial communication networks. He is a member of the IEEE Industrial Electronics Society.

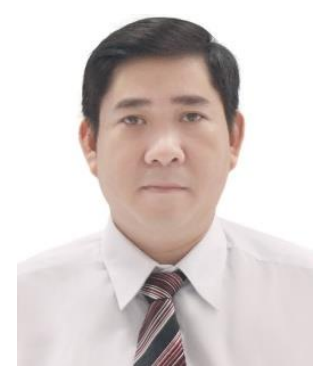

Pham Nhat Phuong was born in Tien Giang, Vietnam. He graduated from the University of Technical Education Ho Chi Minh City, Viet Nam. He received MSc. degrees in Electrical Equipment, Network and Power Station in 2006. Now, he is teaching at the department of electrical and electronics engineering, Ton Duc Thang University, Ho Chi Minh City, Vietnam. His research interests include Evolutionary algorithm, intelligent control system, operation and control power system. 